\title{
Myocardial fibrosis is not associated with reduced quality of life in patients with dilated or hypertrophic cardiomyopathy
}

\author{
Razi Khan ${ }^{1 *}$, David Massel ${ }^{1}$, David Scholl ${ }^{2}$, John Stiratt ${ }^{2}$, Gerald Wisenberg ${ }^{1}$, R Terry Thompson ${ }^{3}$, Frank Prato ${ }^{3}$, \\ Derek Boughner ${ }^{1}$, Maria Drangova², James A White ${ }^{1}$
}

From 2011 SCMR/Euro CMR Joint Scientific Sessions

Nice, France. 3-6 February 2011

\section{Background and objectives}

Patients with Dilated Cardiomyopathy (DCM) and Hypertrophic Cardiomyopathy (HCM) frequently demonstrate non-ischemic pattern myocardial fibrosis (MF) on delayed enhancement magnetic resonance imaging (DE-MRI). The clinical significance of this finding with respect to impact on Quality of Life (QOL) is poorly understood. In this study we identify the prevalence of MF in patients with HCM and DCM and assess its relationship with standardized measures of QOL.

\section{Methods}

One-hundred and seven consecutive patients with either DCM $(n=50)$ or HCM $(n=57)$ referred for MRI evaluation were identified. DCM was defined as a LVEF $<40 \%$ and no significant coronary disease by angiography. HCM was defined by standard echocardiographic criteria. All patients completed both the Minnesota Living With Heart Failure (MLWHF) and SF-12 QOL questionnaires at time of MRI. A standard DE-MRI protocol was performed 10 minutes following the administration of intravenous gadolinium (Gadovist $^{\circ}$, Bayer Inc). DE images were both visually scored using a validated 68 sub-segment segment model and quantitatively analyzed for signal enhancement (threshold $>3$ SD above reference myocardium) using validated commercial software.

\section{Results}

Mean age for DCM and HCM groups was $59( \pm 13.4)$ and $53( \pm 12.1)$ years respectively with a mean ejection fraction of $34.7 \pm 16.9 \%$ and $74.2 \pm 10.8 \%$ respectively. The respective mean NYHA class of the 2 groups was $2.0 \pm 0.9$ and $1.4 \pm 1.1$. The prevalence of any MF on visual scoring was $64 \%$ in the DCM group and $82 \%$ in those with HCM. By quantitative evaluation there was significantly more MF detected in patients with $\mathrm{HCM}$ than in DCM (19.2\% vs. $13.1 \%$ of LV mass $(\mathrm{p}=0.008)$ ). QOL, as assessed by MHLWF, was not significantly different in patients with any MF versus those without for either the DCM group (39.9 vs. 26.1, $\mathrm{p}=0.067$ ) or HCM group (28.7 vs. 26.1, p=0.45). The SF12 physical and mental scores were also similar for both the DCM group ( 46.4 vs. $50.2(\mathrm{p}=0.25)$, and 46.2 vs. 44.4 $(\mathrm{p}=0.83)$, respectively) and HCM group (40.4 vs. 45.5 $(\mathrm{p}=0.36)$, and 46.2 vs. $44.4(\mathrm{p}=0.83)$, respectively). There was no correlation found between the quantitative volume of MF and any QOL score in either patient group.

\section{Conclusion}

MF is common in patients with DCM and HCM. However, its presence and severity is not correlated with reductions in QOL relative to patients without MF. Prospective studies to evaluate the impact of MF on the natural history of disease progression and interim change in QOL are underway.

'Division of Cardiology, Department of Medicine, London Health Sciences

Centre, London, ON, Canada

Full list of author information is available at the end of the article

(c) 2011 Khan et al; licensee BioMed Central Ltd. This is an open access article distributed under the terms of the Creative Commons 


\section{Author details}

'Division of Cardiology, Department of Medicine, London Health Sciences

Centre, London, ON, Canada. ${ }^{2}$ Imaging Research Laboratory - Robarts

Research Institute, University of Western Ontario, London, ON, Canada.

${ }^{3}$ Lawson Health Research Institute, University of Western Ontario, London,

ON, Canada.

Published: 2 February 2011

doi:10.1186/1532-429X-13-S1-P292

Cite this article as: Khan et al:: Myocardial fibrosis is not associated with reduced quality of life in patients with dilated or hypertrophic

cardiomyopathy. Journal of Cardiovascular Magnetic Resonance 201113

(Suppl 1):P292.

Submit your next manuscript to BioMed Central and take full advantage of:

- Convenient online submission

- Thorough peer review

- No space constraints or color figure charges

- Immediate publication on acceptance

- Inclusion in PubMed, CAS, Scopus and Google Scholar

- Research which is freely available for redistribution

Submit your manuscript at 